\title{
Truncated Patch Antenna on Jute Textile for Wireless Power Transmission at $2.45 \mathrm{GHz}$
}

\author{
Kais Zeouga, Lotfi Osman, Ali Gharsallah \\ Department of Physics, UR “CSEHF" 13ES37 \\ Faculty of Sciences of Tunis, University of Tunis \\ El Manar, Tunis 2092, Tunisia
}

\author{
Bhaskar Gupta \\ Department of Electronics and Telecommunication \\ Engineering, Jadavpur University \\ Kolkata - 700 032, India
}

\begin{abstract}
Jute textile is made from natural fibres and is known for its strength and durability. To determine if jute could be used as a substrate for microstrip antennas, its electromagnetic characteristics (permittivity and loss tangent) are measured in the band of $1 \mathrm{GHz}$ to $5 \mathrm{GHz}$. The obtained data are used to compare the performances of a simple rectangular patch antenna resonating at $2.45 \mathrm{GHz}$ on jute with others using different textiles as a substrate. Comparing the simulation results gives an idea of using jute as a substrate for microstrip antennas. In the second part of this paper, a truncated patch antenna on jute is studied to be used for wireless power transmission at $\mathbf{2 . 4 5}$ GHz. The antenna was simulated and then fabricated. The measured reflection shows a shift in the resonance frequency compared to the simulated one. The frequency shift is explained, and a solution is proposed to correct it; a second antenna was fabricated and measured.
\end{abstract}

Keywords-Jute textile; permittivity measurement; loss tangent measurement; patch antenna, truncated patch antenna; frequency shift; wireless power transmission

\section{INTRODUCTION}

Microwave applications are used in different areas and technology advancement gives us the possibility to make new and interesting devices. Many of the applications work in the proximity of the human body to enhance the quality of life [1], [2]. In [3], the authors made a taxonomy of electronic applications on the human body: Body sensor network (BSN), body area network (BAN), wireless body area network (WBAN) [4]. They are used for medical, military and emergency applications, wireless power transmission (WPT) and radio frequency identification (RFID). The devices could be implanted directly into the human body or could be wearable using textile as substrate. In the last years, many antennas have used textile materials as a substrate such as cotton [5], denim [6] and polyester [7]. Every material has its own characteristics which affect the performance of the antennas when they are used as substrate. There are textiles made of natural fibers (cotton, wool) and others made of synthetic materials (polyester, plastic, rubber) [8], [9]. In recent years, using textile as substrate has been used in many microwave applications [10]. In this study, the characteristics of jute are measured in the frequency band $[1,5] \mathrm{GHz}$. This textile is interesting because it's made from natural fibers, so it's environmentally friendly. It's also known for its strength and durability. After measuring the characteristics of jute, its permittivity and tangential losses were compared to ones of other textiles at the frequency $2.45 \mathrm{GHz}$, the different values are used to simulate a rectangular patch antenna resonating at the same frequency. The comparative study is made to define if jute could be used as a substrate for microstrip antennas. Jute is used for the fabrication of clothes and carrying bags that are used for product transport. Therefore, we thought about using jute as substrate to make applications such as WPT or RFID to facilitate the management of storage and transportation of products. In general, textile antennas are related to mobility where a circular polarization is preferred. A truncated patch antenna that easily gives a circular polarization is studied using jute as substrate. The antenna was simulated and optimized to resonate at $2.45 \mathrm{GHz}$. The measurement of the fabricated antenna shows a shift in the resonance frequency. This frequency shift is explained, and a correction method is then proposed.

\section{MEASUREMENT OF JUTE CHARACTERISTICS}

For the measurement of dielectric characteristics, there are two main methods: the non-resonant methods [11] and the resonant methods [12]. The non-resonant methods are based on reflection or reflection/transmission. In the first case (reflection), the permittivity value is given by the information extracted of the reflected electromagnetic wave from free space to the sample. In the second case (reflection/transmission), we use both information of reflection from the substrate and transmission through it to extract the proprieties of the dielectric. The resonance methods are based on the principle that the resonant frequency and the quality factor (Q-factor) of a dielectric resonator with specified dimensions are determined by its permittivity and permeability. Using the resonance perturbation method, the complex permittivity of the measured sample can be extracted. In fact, using a rectangular or circular resonator, its resonant frequency and Q-factor are calculated. Then, the sample is introduced inside the resonator, the resonance frequency and the Q-factor are measured. The frequency shift and the change of the Q-factor give the complex permittivity of the sample using resonanceperturbation theory. The advantage of this method is the narrow band of the cavity resonator, so it is sensitive to perturbations. It also handles high fields which give a substantial variation of the signal even for a small change in permittivity. A new resonance method proposed by $\mathrm{S}$. Sankaralingam is based on a rectangular patch antenna [13], [14]. This method consists of simulating a rectangular patch antenna using an approximate value of permittivity. The antenna is then fabricated, and the resonance frequency is 
measured. The value of this frequency gives the effective permittivity of the substrate using the theory of patch antennas [15].

Jute is a textile made of natural fibers [16]. Fig. 1 shows a photo of a sample of jute; it's filled with air, so a low value of permittivity is expected. The thickness of the sample is 0.5 $\mathrm{mm}$.

For the measurement of permittivity and loss tangent, E4991A RF impedance/material analyzer from Agilent Technologies and the dielectric fixture from Novocontrol Technologies are used to measure the permittivity and loss tangent of the sample. Fig. 2 and 3 show the measured permittivity and loss tangent of the jute between 1 and $5 \mathrm{GHz}$, respectively.

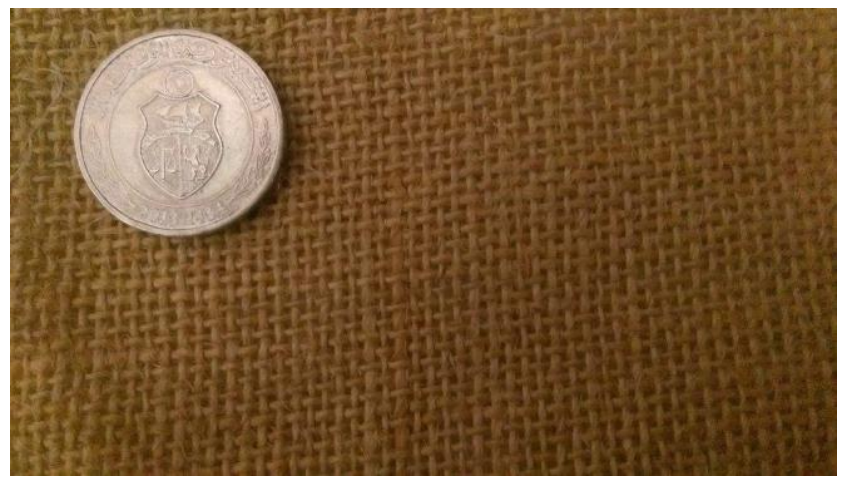

Fig. 1. Sample of a jute textile.

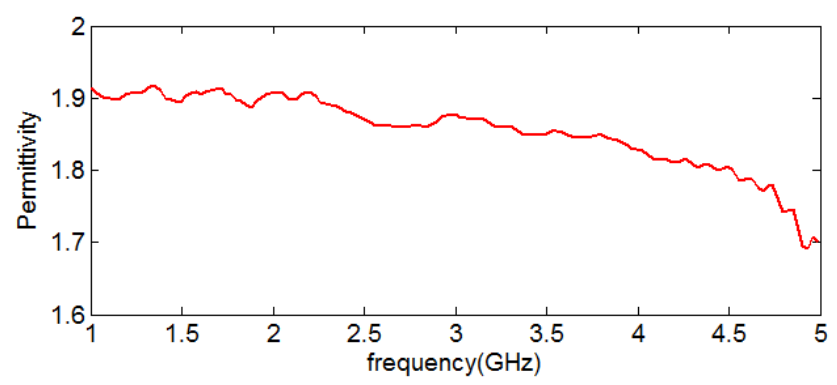

Fig. 2. Measure of the permittivity of the jute versus frequency.

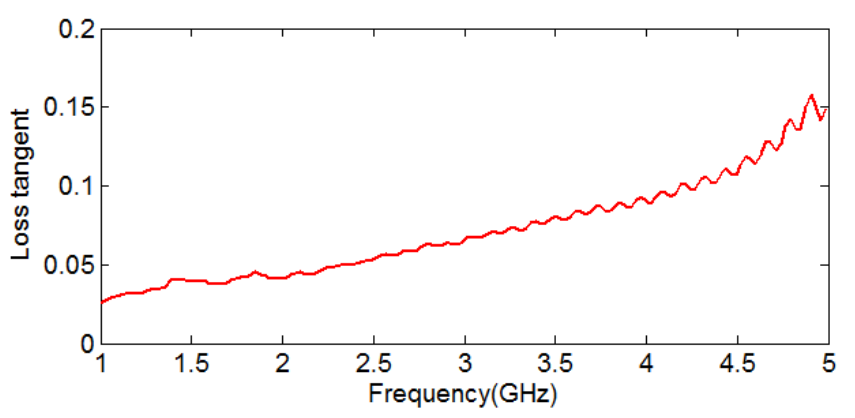

Fig. 3. Measure of the loss tangent of the jute versus frequency.

The permittivity doesn't vary much in the band of measurement, it's between 1.69 and 1.91. This low value of permittivity is expected because jute is filled with air as shown in Fig. 1. However, the loss tangent increases with the frequency, it varies between 0.025 and 0.157 . The values of loss tangent are relatively high compared to other substrates or even other textiles. For this reason, a comparative study based on simulation is made to evaluate the performance of an antenna on jute compared to other textiles.

\section{COMPARATIVE STUdy OF A Simple PATCH ANTENNA USING JUTE AND OTHER TEXTILES AS SUBSTRATE}

At the frequency $\mathrm{fr}=2.45 \mathrm{GHz}$, the jute's permittivity is 1.87. In [17], a width " $w$ " that gives a resonant patch at the frequency fr is given by (1).

$$
w=\frac{1}{2 f_{r} \sqrt{\mu_{0} \varepsilon_{0}}} \sqrt{\frac{2}{\varepsilon_{r}+1}}=\frac{c}{2 f_{r}} \sqrt{\frac{2}{\varepsilon_{r}+1}}
$$

The finite dimensions of the patch will introduce a phenomenon called fringing effect. It is as if the patch was done on a substrate with a different permittivity called effective

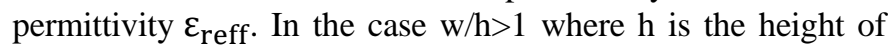
the substrate, $\varepsilon_{\text {reff }}$ is given by (2) [18].

$$
\varepsilon_{\text {reff }}=\frac{\varepsilon_{\mathrm{r}}+1}{2}+\frac{\varepsilon_{\mathrm{r}}-1}{2}\left[1+12 \frac{\mathrm{h}}{\mathrm{w}}\right]
$$

The fringing effect makes the electrical dimensions of the patch different from its physical ones. The electrical length is equal to the physical length adding $\Delta \mathrm{L}$ in each side. Reference [19] gives an approximate value of $\Delta \mathrm{L}$ described by (3).

$$
\frac{\Delta L}{h}=0.412 \frac{\left(\varepsilon_{\text {reff }}+0.3\right)\left(\frac{\mathrm{w}}{\mathrm{h}}+0.264\right)}{\left(\varepsilon_{\mathrm{reff}}-.258\right)\left(\frac{\mathrm{w}}{\mathrm{h}}+0.8\right)}
$$

So, Leff $=\mathrm{L}+2 * \Delta \mathrm{L}$, we can deduce the actual length of the patch using (4).

$$
L=\frac{1}{2 f_{r} \sqrt{\varepsilon_{\text {reff }}} \sqrt{\mu_{0} \varepsilon_{0}}}-2 \Delta L
$$

In this section, a simple patch antenna resonating at 2.45 $\mathrm{GHz}$ is simulated using different textile substrates to compare jute with natural textiles (cotton, Denim) and with synthetic textiles (Polyester, Cordura). Table I shows the characteristics (permittivity and loss tangent) of each textile at $2.45 \mathrm{GHz}$ [20]. The width (w) and length (L) of the patch depend on the permittivity value of the substrate as are given by (1) and (4).

TABLE. I. ELECTROMAGNETIC CHARACTERISTICS OF DIFFERENT TEXTILE MATERIALS AT $2.45 \mathrm{GHz}$

\begin{tabular}{|l|l|l|}
\hline Textile & Permittivity & Tan $\boldsymbol{~}$ \\
\hline Jute & 1.87 & 0.052 \\
\hline Cotton & 1.61 & 0.0138 \\
\hline Denim & 1.59 & 0.031 \\
\hline Polyester & 1.44 & 0.01 \\
\hline Cordura & 1.9 & 0.0098 \\
\hline
\end{tabular}

Different antennas are simulated and optimized using CST Microwave Studio. The same height of $1.5 \mathrm{~mm}$ is for all the textiles, so the comparison of the performance is based only on electromagnetic characteristics. Table II exhibits the performance of a patch antenna made on jute compared to others made on different textiles resonating at the same frequency $2.45 \mathrm{GHz}$. The effect of the permittivity and tan $\delta$ values is shown by the given results. When permittivity increases, the patch surface is reduced as explained in equation (1), but the radiation efficiency Qr decreases. When the $\tan \delta$ increases, the gain is reduced, and the bandwidth is enlarged. Table II shows that the performances of antennas made of 
synthetic textiles are much better than those made of natural textiles in terms of gain and efficiency. This is due to the low value of their $\tan \delta$. Comparing the performance of the patch antenna made of jute with that made of cotton and denim, we notice that the jute patch is the most compact because of its higher permittivity at $2.45 \mathrm{GHz}$; it has the largest bandwidth and its angular width at $-3 \mathrm{~dB}$ is slightly larger, but its gain is lower due to the high value of tang $\delta$. This low value of gain could be a problem for some applications that need high power or deal with long distances. The results given in Table II are correlated to the data given in Table I. At the resonance frequency $2.45 \mathrm{GHz}$, all the antennas are well matched and the bandwidth (BW) increases with the permittivity and the loss tangent values. This can be explained by the relation $B W \approx \frac{1}{Q}$ where $\mathrm{Q}$ is the quality factor [21].

TABLE. II. PERformance COMPARISON OF ANTENNAS USING DifFERENT TEXTILE MATERIALS AS SubSTRATE

\begin{tabular}{|c|c|c|c|c|c|c|c|c|}
\hline Textile & $\begin{array}{l}S_{11} \\
(d B)\end{array}$ & $\begin{array}{l}\text { Band } \\
\text { Width } \\
\text { (MHz) } \\
\end{array}$ & $\begin{array}{l}\text { Angular } \\
\text { width }\left({ }^{\circ}\right) \\
\left(\phi=90^{\circ}\right) \\
\end{array}$ & $\begin{array}{l}\text { Angular } \\
\text { width }\left({ }^{\circ}\right) \\
\left(\phi=0^{\circ}\right) \\
\end{array}$ & $\begin{array}{l}\text { Directivity } \\
\text { (dBi) }\end{array}$ & $\begin{array}{l}\text { Gain } \\
\text { (dB) }\end{array}$ & $\begin{array}{l}\text { Efficiency } \\
(\%)\end{array}$ & $\begin{array}{l}\text { Patch } \\
\text { surface }\left(\mathrm{cm}^{2}\right)\end{array}$ \\
\hline Jute & -24.46 & 117 & 73.6 & 77.9 & 7.9 & 1.98 & 25 & 18.18 \\
\hline Cotton & -28.33 & 54 & 66.4 & 76.1 & 8.41 & 6.05 & 58 & 20.7 \\
\hline Denim & -32.19 & 87 & 68.7 & 75.3 & 8.36 & 4.26 & 38 & 21.25 \\
\hline Polyester & -26.8 & 55 & 65.1 & 73.1 & 8.73 & 6.9 & 65 & 23.66 \\
\hline Cordura & -29.6 & 52 & 71 & 77.8 & 8 & 6.12 & 65 & 18.18 \\
\hline
\end{tabular}

\section{Study of a TRUnCATEd Patch Antenna ON JUTE}

For wireless power transmission, a circular polarization is preferred to reduce losses due to polarization mismatch. The truncated patch antenna is a simple structure that easily gives a circular polarization [22], [23]. The dimension and the direction of the truncations are responsible for axial ratio variation and then the polarization. CST MWS software is used for simulation and optimization. The antenna is simulated using one layer of jute and the gain was very low because of the high value of $\tan \delta$ and the low thickness of the substrate. The low thickness of jute does not allow a constructive superposition of the wave $2.45 \mathrm{GHz}$. For this reason, the antenna is simulated using different numbers of layers. Table III shows the gain of the simulated antenna for each number of layers. The gain increases with the number of layers. Using six layers $(3 \mathrm{~mm})$ gives good simulated gain, but the choice is fixed to use only three layers $(1.5 \mathrm{~mm})$. This choice is made for comfort reasons, as the structure will be used near the human body (on clothes), it is preferred to reduce the thickness of the antenna as possible. The choice is a compromise between the gain and the comfort. The dimensions (in $\mathrm{mm}$ ) of the optimized antenna using three layers of jute are represented in Fig. 4.

TABLE. III. GAIN OF THE ANTENNA FOR DIFFERENT NUMBERS OF USED JUTE LAYERS

\begin{tabular}{|l|l|l|}
\hline Number of layers & Height $(\mathbf{m m})$ & Gain $(\mathbf{d B})$ \\
\hline 1 & 0.5 & -2 \\
\hline 2 & 1 & 0.4 \\
\hline 3 & 1.5 & 1.89 \\
\hline 4 & 2 & 2.8 \\
\hline 5 & 2.5 & 3.2 \\
\hline 6 & 3 & 4.23 \\
\hline
\end{tabular}

Fig. 5 to 8 show the simulated results of the reflection coefficient, the radiation pattern in E-plan, the radiation pattern in $\mathrm{H}$-plan and the axial ratio, respectively. At $2.45 \mathrm{GHz} \mathrm{S} 11=-$ $30 \mathrm{~dB}$, the antenna is well adapted. From Fig. 6, we can notice a small deviation in the radiation pattern; the main lobe magnitude is at $5^{\circ}$, the angular width is $75^{\circ}$. For many applications, an antenna is considered circularly polarized when its axial ratio is less than $5 \mathrm{~dB}$. Fig. 8 shows the axial ration of the truncated patch antenna on jute, the antenna is circularly polarized from Theta $=-110^{\circ}$ to Theta $=62^{\circ}$.

We can say that the antenna is circularly polarized when there is a maximum of radiation. The maximum gain is 1.89 $\mathrm{dB}$. The characteristics of the antenna are suitable for WPT.

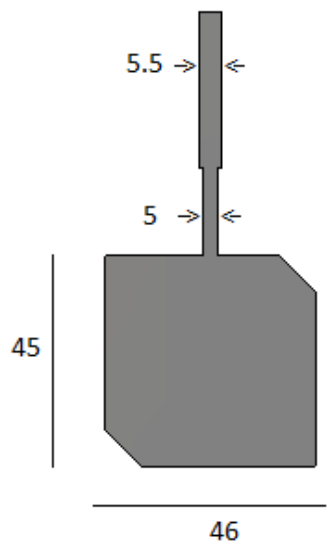

Fig. 4. Dimensions of the truncated patch on jute (in $\mathrm{mm}$ ).

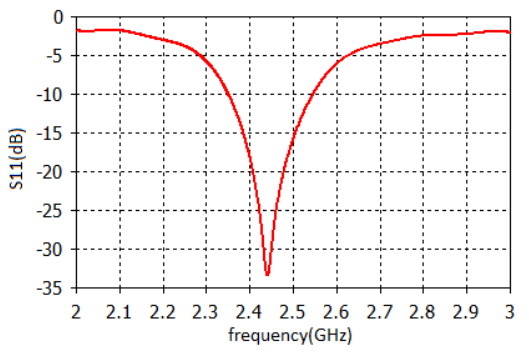

Fig. 5. Reflection coefficient of the simulated patch antenna on jute. 


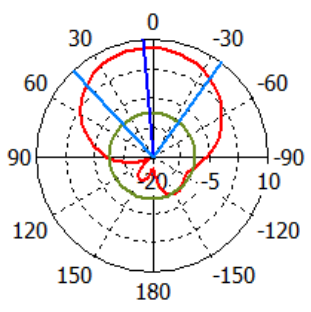

Fig. 6. Radiation pattern E-plan at $2.45 \mathrm{GHz}$.

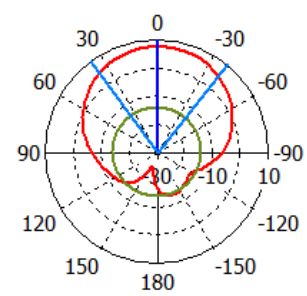

Fig. 7. Radiation pattern in H-plan at $2.45 \mathrm{GHz}$.

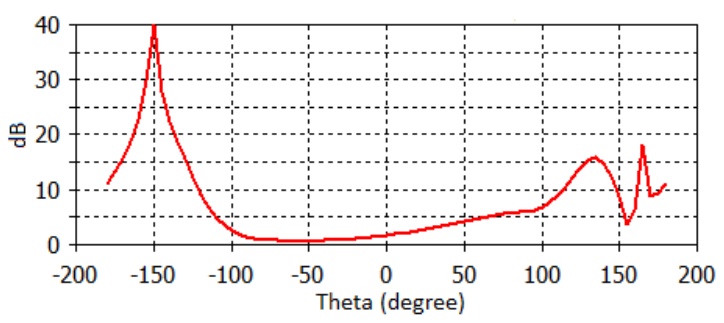

Fig. 8. Axial ratio of the truncated patch on jute at 2.45 .

The antenna was fabricated and then measured. When measuring the reflection coefficient, a shift in the resonance frequency is noticed. The measured resonance frequency is 2.8 $\mathrm{GHz}$ instead of $2.44 \mathrm{GHz}$ in the simulation. This frequency shift could be explained using three layers. The use of multiple layers induces an air gap between every two layers that reduces the global permittivity of the substrate. In the next section, a method is proposed to find the global permittivity of three layers of jute and correct the frequency shift.

\section{FREQUENCY SHIFT CORRECTION FOR TRUNCATED PATCH ON THREE LAYERS OF JUTE}

A frequency shift is noticed between the simulated and measured results that can be explained by the air gap between the layers. This air gap will reduce the permittivity of the global substrate, the three layers of jute will be considered as a substrate having a lower permittivity than measured for jute. To find the global permittivity, a solution is then proposed. This is to simulate the antenna by decreasing the permittivity value of the substrate until getting a resonating frequency at 2.8 $\mathrm{GHz}$. After optimizations, we got a resonance at $2.81 \mathrm{GHz}$ for a permittivity value $\varepsilon_{1}=1.31$. This value will be considered as the permittivity of three layers of jute. Using this value, the antenna is optimized to resonate at $2.45 \mathrm{GHz}$. Fig. 9 shows the dimensions in $\mathrm{mm}$ of the antenna. The antenna was then fabricated and measured. Fig. 10 shows the fabricated antenna under measure. Fig. 11 shows the simulated and measured reflection coefficient. A good agreement is then observed. The proposed method of correction is efficient and the effective permittivity of three layers of jute is 1.31 at $2.45 \mathrm{GHz}$.

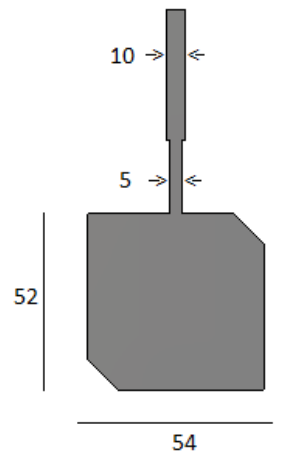

Fig. 9. Dimensions (in mm) of a truncated patch on jute with corrected value of permittivity.

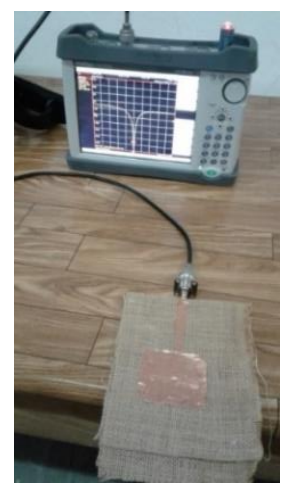

Fig. 10. The fabricated antenna under test.

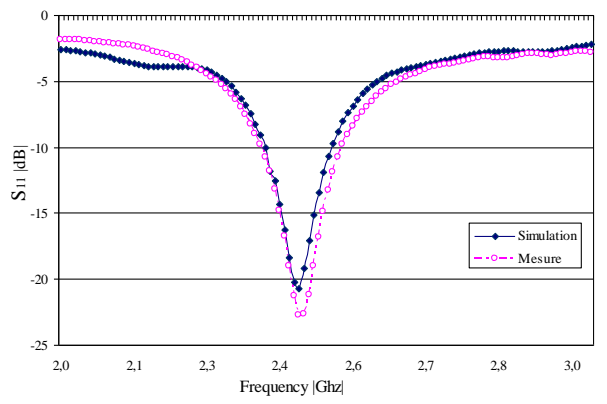

Fig. 11. Reflection coefficient of the truncated patch on jute.

The permittivity of jute is measured from 1 to $5 \mathrm{GHz}$, but these values could be considered only for one layer. Using more layers will reduce the global permittivity and then will induce errors in calculations and simulations. This variation of permittivity concerns all textiles and must be considered when using more than one layer.

\section{CONCLUSION}

In this paper, the electromagnetic characteristics of jute are measured to find if it's suitable for WPT and other microwave applications. The measured results were compared to those of other textiles at the frequency $2.45 \mathrm{GHz}$. The loss tangent of jute is relatively high. Therefore, a simple patch antenna made on natural and synthetic textiles including jute were simulated to compare their performances. Antennas made on synthetic textiles have better gain due to their low $\tan \delta$. Comparing performances of jute and other textiles made of natural fibres, jute has a compact size and a large bandwidth, but its gain is 
very low. Antennas with circular polarization are very important for WPT and wearable microwave applications. A truncated patch antenna resonating at $2.45 \mathrm{GHz}$ using three layers of jute is designed. The simulated antenna presents the required characteristics for WPT. The measurement of the reflection coefficient shows a shift in the resonance frequency compared to the simulated one due to the use of multiple layers. In fact, using more than one layer, induce more air and then reduce the global permittivity value. To correct this shift, the value of permittivity was changed on the simulated antenna until getting a resonance in the same frequency as the measured one. The obtained permittivity is considered as the global permittivity of three layers of jute. Using this value, we designed another antenna. The simulated and measured results have a good agreement proving the efficiency of the proposed method of correction. Based on the obtained results, we can confirm that jute is a good substrate for WPT and wearable microwave applications.

\section{ACKNOWLEDGMENT}

This research work is supported by a project under the scheme of Indo-Tunisian Program of Cooperation in Science and Technology sanctioned by DST (India) and MHESR (Tunisia) bearing Sanction Order No. INT/Tunisia/P-02/2012 dated 01/03/2013.

\section{REFERENCES}

[1] M. E. Jalil, M. K. A. Rahim, N. J. Ramly, N. A. Samsuri, K. Kamardin, M. A. Abdullah, and H. A. Majid, "Planar Textile Antenna for Body Centric Wireless Communication System," Progress In Electromagnetics Research C, Vol. 54, 29-40, 2014.

[2] H. Nawazl and M. A. B. Abbasi, "On-body Textile Antenna Design and Development for Body-centric Wireless Communication Systems," 12th International Bhurban Conference on Applied Sciences and Technology (IBCAST), 13-17 Jan. 2015.

[3] M. Chen, S. Gonzalez, A. Vasilakos, H. Cao, and V. C. M. Leung, "Body Area Networks: A Survey," (C) Springer Science+Business Media, LLC 2010.

[4] Fatemeh Rismanian Yazdi, Mehdi Hosseinzadeh and Sam Jabbehdari, "A Review of State-of-the-Art on Wireless Body Area Networks" International Journal of Advanced Computer Science and Applications (IJACSA), 8(11), 2017. http://dx.doi.org/10.14569/IJACSA.2017.081154

[5] S. Sankaralingam and B. Gupta, "Development of Textile Antennas for Body Wearable applications and investigations on their performance under bent conditions," Progress In Electromagnetics Research B, Vol. 22, 53-71, 2010.

[6] M. Grilo and F. S. Correra, "Parametric Study of Rectangular Patch Antenna Using Denim Textile Material," International Microwave \& Optoelectronics Conference (IMOC), 4-7 Aug. 2013.

[7] E. G. Lim, Z. Wang, M. Leach, R. Zhou, K. L. Man, and N. Zhang, "Compact Size of Textile Wearable Antenna," Proceedings of the
International MultiConference of Engineers and Computer Scientists, Vol II, IMECS 2014, March 12 - 14, 2014, Hong Kong.

[8] A. Priya, A. Kumar, and B. Chauhan, "A Review of Textile and Cloth Fabric Wearable Antennas," International Journal of Computer Applications (0975 - 8887), Vol. 116 - No. 17, April 2015.

[9] Saadat Hanif Dar, Jameel Ahmed and Muhammad Raees, "Characterizations of Flexible Wearable Antenna based on Rubber Substrate" International Journal of Advanced Computer Science and Applications (IJACSA), 7(11), 2016.

http://dx.doi.org/10.14569/IJACSA.2016.071124

[10] M. K. Elbasheer, A. Abuelnuor, M. K. A. Rahim, and M. E. Ali, "Conducting Materials Effect on UWB Wearable Textile Antenna," Proceedings of the World Congress on Engineering 2014 Vol I, WCE 2014, July 2 - 4, 2014, London, U.K.

[11] R. Moro, S. Agneessens, H. Rogier, A. Dierck, and M. Bozzi, "Textile Microwave Components in Substrate Integrated Waveguide Technology," IEEE Transactions on Microwave Theory and Techniques, Vol. 63, No. 2, February 2015.

[12] M. T. Jilani, M. Z. Rehman, A. M. Khan, M. T. Khan, and S. M. Ali, “A Brief Review of Measuring Techniques for Characterization of Dielectric Materials," International Journal of Information Technology and Electrical Engineering, vol. 1, issue 1, December 2012.

[13] J. Sheen, "Study of microwave dielectric properties measurements by various resonance techniques," Elsevier, Measurement 37 (2005) 123130.

[14] S. Sankaralingam and B. Gupta, "Determination of Dielectric Constant of Fabric Materials and Their Use as Substrates for Design and Development of Antennas for Wearable Applications," IEEE Transactions on Instrumentation and Measurement, Vol. 59, No. 12, December 2010.

[15] S. Sankaralingama, S. Dhar, B. Gupta, L. Osman, K. Zeouga, and A. Gharsallah, "Performance of Electro-Textile Wearable Circular Patch Antennas in the Vicinity of Human Body at $2.45 \mathrm{GHz}$," Journal of Procedia Engineering by Elsevier, Vol. 64, pp. 179-184, 2013.

[16] C. A. Constantine, A. Balanis, "Antenna Theory: Analysis and Design", 2nd edition, John Wiley \& Sons, INC.

[17] L. Ammayappan, L. K. Nayak, D. P. Ray, S. Das, and A. K. Roy, "Functional Finishing of Jute Textiles-An Overview in India," Journal of Natural Fibers, 10:390-413, Copyright (C) Taylor \& Francis Group, LLC, 2013.

[18] I. J. Bahl, P. Bhartia, "Microstrip Antennas," Artech House, Dedham, MA, 1980.

[19] E. O. Hammerstad, "Equations for Microstrip Circuit Design," Proc. Fifth European Microwave Confeence, pp. 268-272, 1-4 Sept. 1975.

[20] R. Salvado, C. Loss, R. Gonçalves, and P. Pinho, "Textile Materials for the Design of Wearable Antennas: A Survey," Sensors 2012, 12, pp. 15841-15857.

[21] M. Capek, L. Jelinek, and P. Hazdra, "On the Functional Relation between Quality Factor and Fractional Bandwidth," Journal of LATEX class files, Vol. 6, No. 1, January 2007.

[22] A. K. Aswad, F. Abdulrazak, T. A. Rahman "Design and development of high gain wideband circularly polarized patch antenna," IEEE International RF and microwave conference, 2008.

[23] Chithra Liz Palson, Ajeena Elza Sunny, D. D. Krishna, "circularly polarized square patch antenna with improved axial ratio bandwidth," IEEE Annual India Conference (INDICON), 2016. 